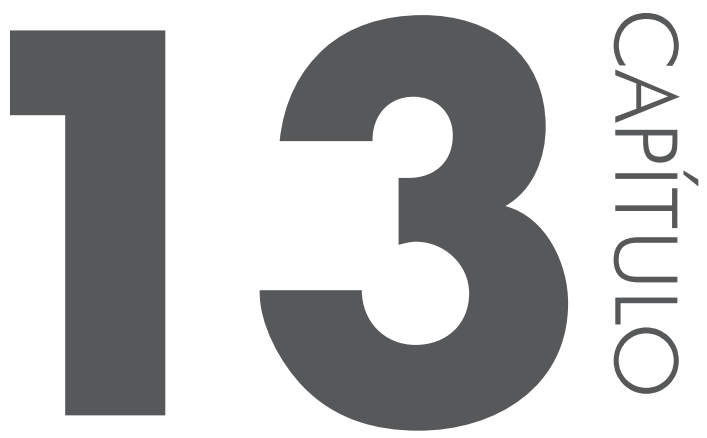

\title{
A ESTIMULAC̣ÃO PRECOCE DE CRIANÇAS PÚBLICO-ALVO DA EDUCAÇÃO ESPECIAL NA EDUCAC̣ÁO INFANTIL
}

Gabriela Silva Braga Borges ${ }^{1}$ Maria Marta Lopes Flores ${ }^{2}$ Janaina Cassiano Silva ${ }^{3}$

Resumo: Este artigo tem o objetivo de abordar a estimulação precoce como um importante programa educacional para o desenvolvimento das crianças públi-

1 Unidade Acadêmica Especial de Educação, Universidade Federal de Goiás/Regional Catalão, Catalão/GO, Brasil

2 Unidade Acadêmica Especial de Educação, Universidade Federal de Goiás/Regional Catalão, Catalão/GO, Brasil

3 Unidade Acadêmica Especial de Educação, Universidade Federal de Goiás/Regional Catalão, Catalão/GO, Brasil

E-mail de contato: gabysbborges@hotmail.com 
co-alvo da educação especial na faixa etária de 0 a 3 anos. Para isto partimos da visão de Vygotski (2012) de que a criança público-alvo da Educação Especial está sujeita as mesmas leis de desenvolvimento que a criança sem deficiência, porém, no seu desenvolvimento, há algumas especificidades. Desta forma, a educação da criança público-alvo da Educação Especial deve ser a mesma compartilhada por todos, mudando apenas os estímulos e havendo a necessidade de uma revisão de planejamentos e orientações. Assim, a estimulação precoce, como forma preventiva, tem como objetivo principal fazer com que a criança se desenvolva potencialmente, possibilitando a mais completa integração com a família, a escola e a sociedade. Sob essa nova visão, é que entendemos a Educação Infantil como um dos locais adequado para o oferecimento de serviços de estimulação precoce, pois prima pela qualidade, fundamentando-se no cuidar, no educar e no brincar, por meio dos quais se busca o desenvolvimento integral da criança público-alvo da educação especial e sua inserção no meio social.

Palavras-chave: Estimulação precoce. Crianças público-alvo da educação especial. Educação infantil.

Abstract: This article aims to address the Early Stimulation as an important educational program for the development of the target group of special education children aged zero to three years. For this we start from the view of Vygotsky (2012) that the target public child's special education is subject to the same laws of development that children without disabilities, but in its development a few specifics. Thus, the target audience child's education of special education should be shared by all the same, changing only the stimuli and there is the need for a review of plans and guidelines. Thus, early stimulation as preventive aims to get children to develop potentially enabling tighter integration with the family, school and society. Under this new view is that we understand early childhood education as one of the suitable places for offering early intervention services because on quality taking account of the care, in education and play, through which seeks the integral development of children target audience of special education and its place in the social environment.

Keywords: Early stimulation. Target public children of special education. Early childhood education.

\section{INTRODUC̣ÃO}

Vivemos em uma sociedade em que os padrões estabelecidos para determinar um sujeito ideal (físico, moral, intelectual) são definidos conforme os padrões vigentes em cada época.

Sob a égide da inclusão, constantemente vemos a afirmação de que as diferenças são valorizadas, entretanto, quando aprofundamos nosso olhar para as 
relações estabelecidas com as pessoas com deficiência, notamos que elas estão ainda envoltas numa névoa de preconceitos em que a visão da segregação se faz muito presente.

Com as crianças público-alvo da educação especial ${ }^{4}$, esse pensamento também é frequente, pois ainda é pouco difundido que as interações educacionais adequadas, realizadas desde os primeiros meses de vida, proporcionarão o pleno desenvolvimento daquela criança.

Vygotski (2012) aponta que quando uma criança com deficiência nasce, ela já ocupa um lugar diferenciado na sociedade, ou seja, vai estar sujeita aos estigmas, aos padrões históricos e culturais impostos.

A deficiência cria um desvio do tipo humano biológico estabelecido, ao provocar a perda de algumas funções, a falência ou deterioração de alguns órgãos, a reestruturação mais ou menos substancial de todo o desenvolvimento sobre novas bases, conforme o novo tipo; perturba, logicamente, o curso normal do processo de fixação da criança na cultura, já que a cultura está acomodada a uma pessoa sem deficiência, típica, está adaptada a sua constituição, e o desenvolvimento atípico condicionado pela deficiência, não pode fixar direta e imediatamente na cultura a criança com deficiência (VYGOTSKI, 2012, p. 27, tradução nossa).

Neste sentido não se deve evidenciar a deficiência de tal modo que possa ser causa da invalidez social da criança. Deve-se focalizar o que a criança pode alcançar e não aquilo que ela não pode fazer devido as suas limitações.

Ainda, de acordo com Vygotski (2012), a criança público-alvo da educação especial está sujeita as mesmas leis de desenvolvimento que a criança sem deficiência, porém, no seu desenvolvimento, há algumas especificidades.

Nesta lei, reside a mais importante posição de princípio da pedagogia da infância deficiente, ou seja: a essência psicológica da formação de reações condicionadas no cego (a percepção tátil dos pontos durante a leitura) e no surdo ( a leitura labial) é exatamente a mesma que na criança sem deficiência, e, por conseguinte, também a natureza do processo educativo das crianças deficientes, no fundamental, é a mesma que quando se trata de crianças sem deficiência (VYGOTSKI, p. 76, 2012, tradução nossa).

Desta forma, a educação da criança público-alvo da educação especial deve ser a mesma compartilhada por todos, mudando apenas os estímulos e havendo a necessidade de uma revisão de planejamentos e orientações, de modo a garantir uma maior experiência social e um maior desenvolvimento da criança com deficiência.

4 São crianças com deficiência, transtornos globais do desenvolvimento e altas habilidades/ superdotação. 
Segundo Vygotski (2012), não há como definir o grau de desenvolvimento ao qual a pessoa com deficiência pode chegar, pois isso dependerá da compensação e dos estímulos que abrirão novos caminhos para o desenvolvimento.

A educação de crianças com diferentes deficiências deve firmar-se em que, simultaneamente com a deficiência também estão dadas as tendências psicológicas de orientação oposta, estão dadas as possibilidades compensatórias para superar a deficiência e que precisamente são essas as que aparecem em primeiro plano no desenvolvimento da criança e devem ser incluídas no processo educativo como sua força motriz. Construir todo o processo educativo seguindo as tendências naturais da supercompensação significa não atenuar as dificuldades que derivam da deficiência, mas estender todas as forças para compensá-las, explicar somente tal tarefa e fazê-lo em tal ordem, que respondam a graduação do processo de formação de toda personalidade sob um novo ângulo (VYGOTSKI, 2012, p. 47 tradução nossa).

Deste modo, a aprendizagem da criança público-alvo da educação especial não está ligada à forma convencional de ensino, mas vai aprender e consequentemente se desenvolver por meio de aparatos diferenciados, sob novas estratégias de ensino. Portanto, o (a) professor (a) necessita ter um conhecimento científico para poder desenvolver um trabalho que possibilite o seu desenvolvimento integral.

Quando o professor se depara em sala de aula com uma criança com deficiência intelectual, visual, auditiva, física ou múltipla, se estabelece um questionamento sobre sua prática pedagógica. Muitas vezes, esse (a) professor (a) pergunta-se: Como posso trabalhar com esta criança? Que estratégias, utilizo para promover o desenvolvimento delas? Como posso estimular o desenvolvimento físico, cognitivo e social da criança público-alvo da educação especial presente em meu agrupamento?

É sob essas indagações que a estimulação precoce se apresenta como o primeiro programa educacional destinado ao atendimento da criança público-alvo da educação especial.

Os estudos sobre estimulação precoce surgiram nos Estados Unidos da América (EUA) em 1960 e tinham como fundamentos básicos: a carência afetiva, a privação cultural na infância e os estudos da teoria de Piaget. O objetivo dessas pesquisas era atuar no desenvolvimento das crianças com deficiências mentais ou das crianças que apresentavam alguma dificuldade de aprendizagem devido as suas condições de vida (CORREIA, 2011; HANSEL, 2012; PÉREZ-RAMOS; PÉREZ-RAMOS, 1992).

As pesquisas sobre a carência afetiva centravam-se nos seguintes pontos: a importância do papel da mãe como mediadora da estimulação da criança; a privação do afeto como catalizador da deficiência mental; a atuação paterna para 
o estímulo da criança e o vínculo afetivo que deve haver entre mãe e filho para proporcionar uma maior interação (BOWLBY, 1960; HARLOW et al., 1963; SPITZ, 1945, 1965 apud PÉREZ-RAMOS; PÉREZ-RAMOS, 1992). Nota-se, a partir desses estudos, que, muitas vezes, os pais foram considerados a fonte dos problemas das crianças e por isso o foco do trabalho era a criança, não havendo nenhuma relação com o contexto familiar, educacional e comunitário.

Conforme Hansel (2012), os programas de estimulação precoce desse período tinham como características: "O modelo médico, ou seja, trabalho compensatório, baseado na relação profissional-criança, com ênfase na figura do profissional, o qual decidia sobre procedimentos de avaliação e intervenção. Nessa perspectiva, a criança era vista fora dos seus contextos, tendo que alcançar objetivos definidos pelos profissionais para que obtivessem assim maior grau de desenvolvimento" (HANSEL, 2012, p. 49-50).

Já as pesquisas sobre privação cultural começaram a se desenvolver a partir de 1950, sob um enfoque ambiental com consequências educacionais. Os trabalhos realizados procuravam fazer uma análise dos níveis "socioeconômicos, considerando as amplitudes da estimulação ambiental e seus resultados no desenvolvimento infantil” (PÉREZ-RAMOS; PÉREZ-RAMOS, 1992, p. 6), isolando fatores e delineando características de diferentes tipos de estimulação e seus efeitos no desenvolvimento mental. Isso possibilitou discriminar os efeitos específicos da falta de estimulação ambiental, devido à carência cultural nos vários níveis socioeconômicos: as crianças de nível socioeconômico baixo apresentavam um pobre rendimento intelectual, principalmente no seu desenvolvimento verbal; as crianças de nível socioeconômico alto apresentavam um rendimento insuficiente nas áreas cognitivas e motoras (PÉREZ-RAMOS; PÉREZ-RAMOS, 1992).

Esses estudos referentes à carência cultural e afetiva deram corpo à estrutura básica da estimulação precoce. Portanto, essa não surge com o intento de atender apenas às crianças com deficiência, mas seu objetivo principal era o de proporcionar às crianças estímulos para um maior desenvolvimento e rendimento escolar na parte linguística e cognitiva, como afirma Pérez-Ramos e Pérez-Ramos (1992, p. 8): “[...] a estimulação, também denominada estimulação psicossocial, referente às experiências que a criança adquire nos seus primeiros anos de vida, incentivam seu desenvolvimento, especialmente da linguagem, constituindo pressupostos importantes para a aprendizagem escolar. Há evidências de que o enriquecimento do ambiente acelera o processo evolutivo da criança".

As pesquisas da teoria de Piaget proporcionaram, neste período, o desenvolvimento de novos conceitos na área cognitiva e o surgimento de procedimentos e instrumentos mais específicos para a detecção e a avaliação precoce em crianças 
com ou sem deficiência (NASCIMENTO, 2010). "Estes conceitos colocam em evidência que a criança, desde os primeiros anos, revela indícios de desenvolvimento de suas capacidades mentais, tais como a atenção, a percepção, a intencionalidade e a memória, apresentando respostas específicas aos diferentes estímulos sensoriais" (PÉREZ-RAMOS; PÉREZ-RAMOS, 1992, p. 14).

Os estudos piagetianos contribuíram para o surgimento de programas de educação compensatória que deveriam ser iniciados nos primeiros anos de vida da criança, juntamente com um programa adequado ao ambiente familiar e um trabalho sistemático de saúde e de nutrição (PÉREZ-RAMOS; PÉREZ-RAMOS, 1992).

O primeiro programa de intervenção precoce iniciado nos Estados Unidos foi o Head Start, em 1965, com um caráter claramente compensatório, pois sua finalidade era potencializar as competências cognitivas, intelectuais, sociais além da saúde física e mental das crianças vindas de famílias de baixa renda (LOVE et al., 2008 apud ARAÚJO, 2012).

Em 1972, o programa Head Start passou a ser complementado pelo Home Start. De acordo com Pérez-Ramos e Pérez-Ramos (1992, p. 23), o programa Home Start era um programa de demonstração que buscava o desenvolvimento integral da criança em idade pré-escolar de 3 a 5 anos e se diferenciava do Head Start ao proporcionar atendimento à criança por meio do envolvimento da própria família. Esses programas de educação compensatória visavam diminuir os ciclos de pobreza, tendo como base os pressupostos que, dada a plasticidade do desenvolvimento nos primeiros anos de vida, uma intervenção nesse período teria efeitos mais eficazes no desenvolvimento das crianças.

Com a publicação, nos Estados Unidos, da Public Law no 92-142 de 1975 e a Public Law n ${ }^{\circ} 99-457$ de 1986, os programas de estimulação precoce para crianças com deficiência ou em risco tiveram uma rápida expansão, “[...] reconhecendo que as crianças com deficiência devem ter iguais oportunidades para desenvolver o máximo das suas potencialidades" (CORREIA, 2011, p. 49).

Desta forma, concordamos com Sánchez-Caravaca (2006) quando diz que a estimulação precoce, desde o seu início nos anos de 1960, tornou-se um campo de muitas controvérsias tanto pela valorização sociopolítica, quanto pelos sujeitos a quem se deve destinar o atendimento, e também no que diz respeito às estratégias de intervenção. Conforme o autor mencionado, as intervenções estavam centradas quase que de forma exclusiva na criança e tinham por base um modelo clínico em que a maioria dos programas adotava métodos comportamentais que procuravam ensinar às crianças novas habilidades.

$\mathrm{Na}$ década de 1980, aconteceu um novo enfoque nos serviços de estimulação precoce. As pesquisas sobre o desenvolvimento infantil destacaram que o desenvolvimento das crianças é influenciado diretamente pela família e pelo meio 
social, por isso o atendimento à criança com deficiência passa a envolver o grupo familiar e os contextos sociais em que ela está inserida (HANSEL, 2012).

A partir dos anos de 1990, o campo da estimulação precoce sofre a influência de dois modelos explicativos de desenvolvimento: o Ecológico de Bronfenbrenner (1979, 1987 apud HANSEL, 2012) e o Transacional de Sameroff e Chandler (1975 apud HANSEL, 2012). Esses modelos explicativos proporcionaram uma evolução nos serviços de estimulação precoce.

Por influências desses dois modelos explicativos, as práticas de estimulação precoce evoluem para um modelo centrado na família, cujas necessidades e desejos norteiam toda a prestação de serviços, reconhecendo-se que as relações entre os vários membros da família, assim como as relações entre a família e a comunidade em que está inserida são importantes para o funcionamento familiar e para o desenvolvimento da criança (HANSEL, 2012, p. 50).

Essa mudança de visão apontou para a questão do contexto familiar de forma mais precisa, pois deixou de ser um elemento secundário para se tornar "[...] imprescindível em qualquer processo de intervenção" (SÁNCHEZ-CARAVACA, 2006, p. 77).

Vale ressaltar que os programas de estimulação precoce também se desenvolveram em outros países como Argentina, Portugal e Espanha.

Em Portugal, as primeiras experiências tiveram início na década de 1970, com a criação no Centro de Paralisia Cerebral, em Lisboa, de um programa de intervenção precoce para crianças com paralisia cerebral. A partir da publicação do Despacho Conjunto 891/99, as crianças com idade entre 0 e 5 anos de idade, com necessidades educacionais especiais ou em risco de desenvolvê-las, e as suas famílias têm o direito de usufruir dos serviços de intervenção precoce. Em 2009, o Decreto-lei ${ }^{\circ} 281$ cria o Sistema Nacional de Intervenção Precoce na Infância, um conjunto organizado de entidades institucionais e de natureza familiar, com o objetivo de garantir condições de desenvolvimento para as crianças com funções ou estruturas do corpo que limitam o crescimento pessoal, social e a sua participação nas atividades típicas para a idade, bem como para as crianças com risco grave de atraso no desenvolvimento (CAMPOS, 2010).

$\mathrm{Na}$ Argentina, a estimulação precoce começou a ser trabalhada pelo intermédio da médica neuropediatra Lydia Coriat, entre os anos de 1960 e os de 1970, tendo como foco uma visão psicanalítica. Segundo essa pesquisadora, os bebês com Síndrome de Down, para se desenvolverem, necessitariam trabalhar a sua condição orgânica, seus limites no desenvolvimento e a sua constituição psíquica, de uma forma interdisciplinar, buscando a produção de um sujeito de desejo (COSTA, 2013). 
A estimulação precoce deveria ser realizada por meio de técnicas psicopedagógicas e psicomotoras, com fundamentos teóricos baseados no conhecimento da teoria da maturação neurológica, da teoria do desenvolvimento cognitivo e da teoria do desenvolvimento afetivo". Dessa forma, estabeleceu parâmetros para a realização dos atendimentos propostos. Justificou o tratamento em estimulação precoce como "meio de propiciar a produção/parição de um sujeito do desejo", alertando que "não interessa a produção de autômatos por melhor que funcionem” (CORIAT, 1997, p.72 apud COSTA, 2013, p. 24-25).

$\mathrm{Na}$ Espanha, a estimulação precoce, que atende pelo nome de atención temprana, começou a se desenvolver por volta de 1979, a partir da Primeira Conferência Internacional sobre Estimulação Precoce em que se estabeleceu a necessidade de uma educação precoce para as crianças com distúrbios ou deficiências. Depois desta conferência, cada região foi desenvolvendo um procedimento particular, que, na maioria das vezes, correspondia a uma solução mais imediata às demandas surgidas e partiam principalmente do esforço e interesse dos pais e dos profissionais na busca do atendimento da criança com deficiência (SÁNCHEZ-CARAVACA; GIL, 2012). Em 1985, o Ministério da Educação espanhol publicou um Decreto Real que organizou o direito de todas as crianças serem educadas em um ambiente normal, estabeleceu as tipologias de centros, apoios e criou as primeiras equipes de multiprofissionais de intervenção precoce em quase todas as províncias espanholas. Essas equipes colaboraram para a inscrição experimental de crianças com deficiências, menores de 3 anos, em escolas maternais (SÁNCHEZ-CARAVACA; GIL, 2012).

\section{OBJETIVO}

Este artigo tem o objetivo de abordar a estimulação precoce como um importante programa educacional para o desenvolvimento das crianças público-alvo da educação especial na faixa etária de 0 a 3 anos.

\section{METODOLOGIA}

Trata-se de uma pesquisa bibliográfica cuja principal "característica é o fato de que o campo onde será feita a coleta de dados é a própria bibliografia sobre o tema ou objeto que se pretende estudar" (TOZONI-REIS, 2009, p. 25).

A intenção não foi de fazer um levantamento completo do tema, mas selecionar o que pareceu mais pertinente para a construção do artigo, buscando fazer uma relação entre estimulação precoce, crianças público-alvo da educação especial e educação infantil. 


\section{DISCUSSÃO}

\subsection{A estimulação precoce: conceito}

A expressão "estimulação precoce" vem da tradução do termo em espanhol "estimulación temprana" e "estimulación precoz". Ela deriva também do termo em inglês "early stimulation" ou "early intervention" (QUEIROZ; PÉREZ-RAMOS, 1974 apud NASCIMENTO, 2010).

O termo estimulação precoce tem recebido vários significados na prática educacional. Não existe um consenso na literatura quanto ao seu uso, podendo serem encontradas outras nomenclaturas como: estimulação essencial, educação precoce, atenção precoce, intervenção precoce e intervenção essencial (GORETTI, 2012; COSTA, 2013; HANSEL, 2012).

Esta indefinição quanto à nomenclatura acontece pelos significados que se dão aos termos "estimulação" e "precoce". A palavra "precoce" gera alguns equívocos, remetendo a ações antecipadas, prematuras, fora do tempo, no sentido de acelerar o desenvolvimento da criança, tornando-a superdesenvolvida. Entretanto, esse termo deve ser entendido como uma ação pontual, no momento certo, por meio de estímulos adequados e necessários ao bom desenvolvimento da criança público-alvo da educação especial (PAINEIRAS, 2005).

Quanto à palavra "estimulação" deve-se entendê-la como uma forma de "proporcionar à criança diversos tipos de oportunidades de experimentar, explorar e brincar com os objetos ao redor dela. Isso inclui movimentos corporais e o uso de todos os sentidos, principalmente a visão, audição e tato" (WERNER, 1994 apud PAINEIRAS, 2005, p. 51).

Hansel (2012) aponta que a mudança conceitual e terminológica nos programas de estimulação precoce acontece porque ela tinha como base uma função reabilitadora, centrada basicamente na criança com deficiência ou transtorno. Contudo, tem-se usado o termo "atenção precoce" que implicaria a adoção de uma perspectiva preventiva, social e ecológica do desenvolvimento, na qual a família tem papel preponderante e os serviços são organizados de forma interdisciplinar visando ao desenvolvimento global da criança.

García Sanches (2003) considera que:

A atenção precoce deve ser entendida como um conjunto de atuações dirigidas à criança, à família e ao meio, desenvolvidas pela ação coordenada de profissionais e equipes interdisciplinares, com a finalidade de assegurar os recursos necessários para prevenir, detectar e dar uma resposta imediata, planejada com caráter global, sistemática, dinâmica e integral às necessidades transitórias ou permanentes da população infantil que na primeira infância (0-6 anos), apresenta transtornos em seu desenvolvimento ou risco de tê-los (GARCÍA SANCHES (2003) apud AMBRÓZIO, 2009, p. 23). 
Podemos notar no conceito de atenção precoce uma ampliação do modelo antigo proposto para esse atendimento. Assim, há um entrelaçamento da "vertente da reabilitação da intervenção psicossocial e da educação dando forma a um processo integral que objetiva o desenvolvimento harmônico da criança nos mais diversos contextos" (COSTA, 2013, p. 26-27).

Outro termo adotado em substituição a estimulação precoce é "estimulação essencial", que apresenta uma maior clareza e abrangência da necessidade dessa intervenção. Assim, a estimulação não seria destinada apenas às crianças público-alvo da educação especial, mas a todas as crianças, sejam elas com ou sem deficiências. Segundo Arce e Silva (2012, p. 178), a estimulação não consistiria em adiantar ou antecipar as "perdas futuras, mas sim tomá-la como uma estimulação necessária; uma vez que essa não deve ser somente destinada a crianças comprometidas por alguma disfunção neurológica ou motora específica, mas destinada a todos os bebês”.

Conforme Paineiras (2005), muitos autores diferenciam estimulação precoce da "intervenção precoce". A estimulação precoce teria um caráter socioeducativo, buscando promover uma melhora na qualidade de vida, permitindo à criança adquirir condições internas e externas para constituir-se enquanto "ser, pessoa e sujeito, ultrapassando comprometimentos motores e cognitivos" (PAINEIRAS, 2005 , p. 54). Já a "intervenção precoce" possuiria um significado mais voltado para a prática em si, ou seja, para a formulação e a execução de planos de ação. Esse planejamento de intervenção teria um papel mais abrangente que alcançaria não só a criança, mas sua família ou cuidador e os vários ambientes onde está inserida como: hospitais, escolas, casas. Tudo isso com o intuito de "promover tanto os aspectos profiláticos quanto o diagnóstico de algum desvio no desenvolvimento" (PAINEIRAS, 2005, p. 54).

Já a “educação precoce” estaria voltada “à intervenção ao nível educacional, no sentido de estabelecer um conjunto de medidas que ajudem a criança a adquirir o maior número possível de competências, tendo em vista o seu desenvolvimento" (CORREIA, 2011, p. 52). Assim, a educação precoce seria aquela realizada na rede de ensino, desenvolvida exclusivamente por professores, visando à inclusão da criança público-alvo da educação especial na escola regular.

No entanto, as Diretrizes Educacionais sobre Estimulação Precoce (BRASIL, 1995) adotam o uso do termo "estimulação precoce" por ser um termo já consagrado internacionalmente e por ter o sentido de proporcionar ações que procuram atenuar, evitar ou compensar as deficiências que, por acaso, possam ter nascido com a criança e suas consequências. O documento mencionado define a estimulação precoce como "conjunto dinâmico de atividades e recursos humanos e ambientais incentivadores que são destinados a proporcionar à criança, nos primeiros anos de vida, experiências significativas para alcançar pleno desenvolvimento no seu processo evolutivo" (BRASIL, 1995, p. 11). 
Desta definição, pode-se entender que a estimulação precoce busca proporcionar serviços, apoios e recursos que procuram atender as necessidades das crianças e as da família, apresentando-se como uma importante ferramenta preventiva e assistencial para promover o desenvolvimento infantil. Retira-se, ainda, desta definição, o público-alvo da educação especial a quem é dirigido os serviços de estimulação precoce: crianças pequenas com idade entre 0 e 3 anos que tenham alguma deficiência (física, mental, auditiva, visual ou múltiplas) ou que pertençam ao grupo de alto risco (BRASIL, 1995).

Nos primeiros anos de vida da criança, o desenvolvimento cerebral é mais rápido e alcança maior extensão do que em qualquer outra etapa da vida, mas ele também é mais vulnerável, pois é suscetível a fatores nutricionais, de interação, de cuidado e de estimulação. Neste sentido, ações ideais para a promoção do desenvolvimento infantil são aquelas que permitem antecipar-se ao dano e, de certa forma, preveni-lo. De acordo com García Sanches (2001, 2003 apud HANSEL, 2012), existem três formas de prevenção: a primária, a secundária e a terciária.

A prevenção primária é aquela que é feita antes de qualquer indício de deficiência, risco ou atraso no desenvolvimento, ou seja, são aquelas estratégias que acontecem como prevenção ao aparecimento do transtorno e que se aplicam à população em geral. Essa prevenção caracteriza-se pela "necessidade de otimizar ou manter os níveis de saúde e bem-estar, alcançados pela população infantil, referenda-se por programas antecipatórios que enfatizem o emprego de ações divulgadoras e promocionais, destinadas a fortalecer o processo evolutivo integral na primeira infância" (COSTA, 2013, p. 14). Nela, estão incluídos os serviços de saúde, de educação e sociais.

Já a prevenção secundária estende sua esfera de atuação à criança que, sob o impacto dos fatores de risco, é considerada suscetível à aquisição de distúrbios no seu desenvolvimento. "A implantação de programas compensatórios nesse contexto considera atualmente as classificações de natureza biológica e ambiental, a identificação das características de vulnerabilidade no desenvolvimento infantil e a carência afetiva e sociocultural" (PÉREZ-RAMOS, 1990 apud COSTA, 2013, p. 14). Costa (2013) ainda destaca que o objetivo da prevenção secundária é a detecção e o diagnóstico precoce para poder amenizar as deficiências que já tenham se instalado. Estão inclusos, nessa prevenção, os serviços de obstetrícia, neonatologia, pediatria, os serviços educacionais e sociais e o envolvimento familiar.

No que se refere à prevenção terciária, essa busca minimizar os efeitos e reduzir ao máximo o transtorno ou a deficiência constatada mediante avaliação contínua e acompanhada de oportuna intervenção. Agrupando todas as atividades desenvolvidas com a criança, sua família e o seu meio, objetiva melhorar as condições de desenvolvimento da criança e pode ser feita em hospitais, escolas e pela família. "A prevenção terciária pode ser dividida em quatro etapas: a 
avaliação inicial da criança, a intervenção terapêutica, a avaliação e controle dos resultados e os encaminhamentos de que a criança necessita" (FEAPAT, 2004 apud HANSEL, 2012, p. 33).

De acordo com Soejima e Bolsanello (2012, p. 67): “A prevenção, de qualquer nível, será efetiva quando se fundamentar em teorias sólidas, incluir a criança, sua família e a escola e for conduzida por pessoas capacitadas, capazes de seguir sistematicamente programas e procedimentos de intervenção (BRITO DE LA NUEZ et al., 2006). Além disso, a prevenção deve ser adequada à cultura e à idade das crianças”.

Assim, a estimulação precoce como forma preventiva tem como objetivo principal fazer com que a criança desenvolva potencialmente suas capacidades de desenvolvimento e de bem-estar, possibilitando a mais completa integração com a família, a escola e a sociedade.

\subsubsection{Estimulação precoce, inclusão, Educação Infantil e Atendimento Educacional Especializado}

$\mathrm{Na}$ perspectiva da inclusão, os serviços de estimulação precoce seriam direcionados às crianças em práticas de colaboração, de convivência, de aceitação, que promoveriam a sua interação com a família, com a vizinhança, com a creche e com a escola. Ou seja, a "organização e a execução desses programas implicariam na participação de todos aqueles que convivem e atuam com a criança, além dos profissionais da área da saúde" (OLIVEIRA; PADILHA, 2013, p. 207).

Assim, apresenta-se uma mudança no foco do atendimento e da intervenção das crianças pequenas e dos bebês, havendo um deslocamento desse atendimento das instituições especializadas para as necessidades da família e da criança no espaço escolar e no contexto comunitário, "buscando organizar ambientes adaptados às necessidades das crianças e formas de comunicação e de relações psicoafetivas que possibilitem o seu desenvolvimento integral" (BRUNO, 2006 apud OLIVEIRA; PADILHA, 2013, p. 208).

Sob essa nova visão, é que entendemos a Educação Infantil como um dos locais adequado para o oferecimento de serviços de estimulação precoce. A Educação Infantil é a primeira etapa da Educação Básica e tem por finalidade o desenvolvimento integral da criança até os 5 anos em vários aspectos como os físicos, os psicológicos, os intelectuais e os sociais. Nela, as crianças desenvolvem a linguagem, a psicomotricidade e interagem com o mundo a sua volta. Muitas são as vantagens que uma escola de Educação Infantil proporciona a qualquer criança, independente de sua condição física, intelectual ou emocional (DRAGO, 2014).

$\mathrm{Na}$ Educação Infantil assim como na estimulação precoce, o objetivo principal é fomentar o desenvolvimento global da criança, apregoando a importância 
de estímulos para o desenvolvimento infantil. A estimulação que a criança recebe desde que nasce e que se estende aos primeiros anos de vida é indispensável para o seu desenvolvimento, pois lhe permite atingir novas fases, proporcionando que ela experimente e conviva com pessoas, gerando experiências enriquecedoras. Conforme explica Mendes:

\begin{abstract}
Nos primeiros anos de vida, devem ser abertas janelas de oportunidades para que a criança aprenda determinados tipos de aprendizagem, que se não forem adquiridas neste período crítico se tornam difíceis, quando não impossíveis, de serem adquiridas mais tarde. Assim, as descobertas científicas têm colocado cada vez mais em evidência a importância dos primeiros anos de vida e o papel que o ambiente tem nesse processo, e esse avanço tem implicado uma crescente preocupação social com o cuidado e a Educação Infantil (MENDES, 2010, p. 48).
\end{abstract}

Concordamos com Paineiras (2005, p.71) quando afirma que "um espaço físico e social desprovido de estimulação tem efeitos debilitantes e são fatores causadores ou precipitadores de deficiências, sobretudo no desenvolvimento de capacidades e habilidades cognitivas e sociais”. Assim, estar atento aos fatores emocionais, físicos, sociais e cognitivos significa prevenir eventuais atrasos do desenvolvimento e compensar determinadas carências que podem advir do ambiente familiar (MULAS, 2007).

A educação especial apresenta-se como uma modalidade de ensino transversal que perpassa todos os níveis, etapas e modalidades da educação. A responsabilidade da educação especial é de organizar serviços, recursos e estratégias de acessibilidade, por meio dos quais se busca eliminar barreiras que possam dificultar ou impedir o pleno acesso das pessoas com deficiência à educação.

Outra previsão da educação especial é o Atendimento Educacional Especializado (AEE) que é definido como "um serviço que identifica, elabora e organiza recursos pedagógicos e de acessibilidade, que eliminem barreiras para plena participação dos estudantes, considerando suas necessidades específicas” (BRASIL, 2008, p. 10).

$\mathrm{Na}$ educação infantil, o AEE apresenta-se como uma ferramenta de fundamental importância para o desenvolvimento das crianças com deficiência desde os primeiros anos de vida, dando-lhes "acessibilidade física e pedagógica aos brinquedos, aos mobiliários, às comunicações e informações, utilizando-se da Tecnologia Assistiva como área que agrega recursos e estratégias de acessibilidade" (BRASIL, 2015, p. 4).

A educação é um direito de todas as pessoas. Para a criança com deficiência, esse direito deve garantir o acesso à Educação Infantil e ao Atendimento Educacional Especializado. Deste modo, as creches e pré-escolas precisam elaborar um Projeto Político Pedagógico (PPP) que garanta acesso e permanência das crianças público-alvo da educação especial e também das crianças sem deficiências. 
O Atendimento Educacional Especializado quando previsto no Projeto Político Pedagógico precisa ser organizado conforme o artigo 10 da Resolução $n^{\circ} 04 / 2009$.

I - sala de recursos multifuncionais: espaço físico, mobiliário, materiais didáticos, recursos pedagógicos e de acessibilidade e equipamentos específicos; II - matrícula no AEE de alunos matriculados no ensino regular da própria escola ou de outra escola; III - cronograma de atendimento aos alunos; IV - plano do AEE: identificação das necessidades educacionais específicas dos alunos, definição dos recursos necessários e das atividades a serem desenvolvidas; $\mathrm{V}$ - professores para o exercício da docência do AEE; VI - outros profissionais da educação: tradutor e intérprete de Língua Brasileira de Sinais, guia-intérprete e outros que atuem no apoio, principalmente às atividades de alimentação, higiene e locomoção; VII - redes de apoio no âmbito da atuação profissional, da formação, do desenvolvimento da pesquisa, do acesso a recursos, serviços e equipamentos, entre outros que maximizem o AEE (BRASIL, 2009, p. 2).

Essa previsão, nas creches e pré-escolas, abre a oportunidade para que toda comunidade escolar (pais, alunos, professores, gestores, funcionários) conheçam e participem desse serviço.

Neste sentido, o professor do Atendimento Educacional Especializado assume o papel de fazer a identificação da criança público-alvo da educação especial por meio de um estudo de caso em que são levadas em conta as necessidades e as habilidades da criança. Esse estudo possibilita que sejam propostas formas de eliminar as barreiras existentes no ambiente (BRASIL, 2015).

A partir do estudo de caso, o professor do AEE elabora o plano de Atendimento Educacional Especializado que define o tipo de atendimento destinado à criança; identifica os recursos de acessibilidade necessários; produz e adequa materiais e brinquedos; seleciona os recursos de Tecnologia Assistiva a serem utilizados; acompanha o uso dos recursos no cotidiano da Educação Infantil, verificando sua funcionalidade e aplicabilidade; analisa o mobiliário; orienta os professores e as famílias quanto aos recursos de acessibilidade a serem utilizados e o tipo de atendimento destinado à criança. O professor do AEE também se articula com as demais áreas de políticas setoriais, visando ao fortalecimento de uma rede intersetorial de apoio ao desenvolvimento integral da criança (BRASIL, 2015, p. 05).

Sob esta perspectiva, o atendimento que é feito à criança com deficiência é deslocado da sala de recursos multifuncionais para o contexto da instituição de Educação Infantil. Ou seja, o professor do Atendimento Educacional Especializado irá atuar em todos os ambientes que a criança público-alvo da educação especial frequente na Educação Infantil como: "berçário, solário, parquinho, sala de recreação, refeitório, entre outros, onde as atividades comuns a todas as crianças são adequadas às suas necessidades específicas" (BRASIL, 2015, p. 5). 
Para que haja uma efetiva aplicação do plano elaborado pelo professor do Atendimento Educacional Especializado, há necessidade de uma articulação com o professor regente, com o qual se procura fazer uma discussão das necessidades e das habilidades das crianças público-alvo da educação especial, tendo por base o seu contexto educacional e sempre levando em conta que o Atendimento Educacional Especializado não substitui as atividades curriculares da Educação Infantil.

Então, a principal atribuição do professor do Atendimento Educacional Especializado na Educação Infantil "é identificar barreiras e implementar práticas e recursos que possam eliminá-las, a fim de promover ou ampliar a participação da criança com deficiência em todos os espaços e atividades propostos no cotidiano escolar" (BRASIL, 2015, p. 5).

Para as crianças que possuem uma necessidade específica gerada pela sua deficiência é necessário, além do trabalho do professor do Atendimento Educacional Especializado com o professor regente, o acesso a serviços especiais de ensino como "ensino, tradução e interpretação de Língua Brasileira de Sinais-LIBRAS, de guia intérprete e de apoio às atividades de locomoção, mobilidade, alimentação e cuidados específicos da criança com deficiência” (BRASIL, 2015, p. 6).

Deste modo, o desenvolvimento pode e deve ser potencializado por meio das relações estabelecidas na educação infantil, principalmente quando as relações estão fundamentadas em um projeto político pedagógico direcionado para o desenvolvimento da criança público-alvo da educação especial. Pois essas crianças necessitam de serviços, "estratégias instrucionais, tratamentos terapêuticos, equipamentos especiais ou ambientes estimuladores que sejam diferentes daqueles necessários para as crianças com desenvolvimento normal" (MENDES, 2010, p. 49).

Assim, o trabalho desenvolvido na Educação Infantil deve primar pela qualidade, fundamentando-se no cuidar, no educar e no brincar. Desta forma, as intervenções com as crianças público-alvo da educação especial devem ser realizadas durante as brincadeiras, as rotinas e as atividades que ocorrem ao longo do período que a criança está na escola e devem buscar o desenvolvimento integral por meio de sua inserção no meio social.

\section{CONCLUSÕES}

Diante do exposto, podemos dizer que este artigo teve o objetivo de fazer um estudo da estimulação precoce ao entendê-la como um processo educacional que visa promover o desenvolvimento integral da criança público-alvo da educação especial e que vem passando por transformações e mudanças conforme os ideais político-pedagógicos vigentes em cada período.

No âmbito da rede regular, a estimulação precoce propicia que a criança com deficiência desenvolva de forma plena os aspectos cognitivos, físicos e sociais. 
Assim, as crianças público-alvo da educação especial, presentes na Educação Infantil, só têm a ganhar quando há uma parceria entre o professor do Atendimento Educacional Especializado e o professor da rede regular.

Essa parceria é feita por meio de um planejamento conjunto, da elaboração das atividades e do entendimento que a criança público-alvo da educação especial tem as mesmas condições de desenvolvimento que as crianças sem deficiência, sendo que o que ela precisa é ser estimulada em todas as atividades que são desenvolvidas na educação infantil. Deste modo, quanto mais os professores propiciarem àquelas crianças experiências de aprendizagem, maior será o seu desenvolvimento, pois, como ressalta Vygotski (2012), o bom ensino é aquele que se adianta ao desenvolvimento.

Concordamos com Carneiro (2012, p. 91) quando diz:

O trabalho de colaboração não se destina apenas a favorecer aos alunos com deficiência, mas beneficia a todos os alunos. Construir uma prática flexível capaz de atender as diferenças individuais e oportunizar outras formas de aprendizagem a todos os alunos promove um ambiente educacional democrático e justo, além de promover a prática reflexiva do professor, elemento indispensável para o novo paradigma que a educação inclusiva aponta (CARNEIRO, 2012, p. 91).

Portanto, uma educação infantil inclusiva é aquela que busca estimular o desenvolvimento de todas as crianças que frequentam este espaço. Ou seja, é aquela que vê nas crianças as potencialidades e entende que a diversidade humana não pode ser motivo de exclusão.

\section{REFERÊNCIAS}

AMBROZIO, C. R. Participação de mães na avaliação do desenvolvimento do bebê com Síndrome de Down, realizada pelo psicólogo, na estimulação precoce. 2009. 155 f. Dissertação (Mestrado em Educação) - Universidade Federal do Paraná, Programa de Pós-Graduação em Educação, Curitiba, 2009.

ARAÚJO, E. R. Efeitos de um programa de intervenção precoce baseado no modelo mais que palavras - HANEN, para crianças menores de três anos com risco de autismo. 2012. 138 f. Dissertação (Mestrado em Educação) - Universidade Federal do Rio Grande do Norte, Centro de Ciências Sociais Aplicadas, Programa de Pós-Graduação em Educação, Natal, 2012.

ARCE, A; SILVA, J. C. É possível ensinar no berçário?: o ensino como eixo articulador do trabalho com bebês ( 6 meses a 1 ano de idade). In: ARCE, A; MARTINS, L. M. (Org.). Ensinando aos pequenos de zero a três anos. 2. ed. Campinas: Editora Alínea, p. 163-186. 2012. 
BOWLBY, J. Aflição e luto na infância e na primeira infância. Rio de Janeiro: Companhia Freud, 1960.

BRASIL. Ministério da Educação. Resolução no 4, de 2 de outubro de 2009. Institui Diretrizes Operacionais para o Atendimento Educacinal Especializado na Educação Básica, modalidade Educação Especial. Brasília: MEC, 2009.

BRASIL. Ministério da Educação. Secretaria de Educação Continuada, Alfabetização, Diversidade e Inclusão. Nota Técnica Conjunta n ${ }^{\circ}$ 02/2015/MEC/SECADI/DPEESEB/DICEI. Orientações para a organização e oferta do Atendimento Educacional Especializado na Educação Infantil. 2015.

. Ministério da Educação. Secretaria de Educação Especial. Política de Educação Especial na perspectiva da Educação Inclusiva. Brasília- DF: MEC, 2008.

- Ministério da Educação. Diretrizes educacionais sobre estimulação precoce: o portador de necessidades educativas especiais. Brasília: MEC, Secretaria de Educação Especial (SEESP), 1995.

CAMPOS, A. R. Intervenção precoce e a família: estudo de caso de uma criança em risco. 2010. 88 f. Dissertação (Mestrado em Educação) - Universidade do Minho, Instituto de Educação. Minho/Portugal, 2010.

CARNEIRO, R. U. C. Educação inclusiva na Educação Infantil. Práxis Educacional, Vitória da Conquista, v. 8, n. 12, p. 81-95, jan./jun. 2012.

CORREIA, N. C. C. C. A importância da intervenção precoce para as crianças com autismo na perspectiva dos educadores e professores de educação especial. 2011. 143 f. Dissertação (Mestrado em Ciências da Educação) - Escola Superior de Educação Almeida Garrett,. Lisboa, Portugal, 2011.

COSTA, R. C. G. F. O estado do conhecimento sobre estimulação precoce no conjunto de teses e dissertações brasileiras no período entre 2000 e 2011. 2013. 123 f. Dissertação (Mestrado em Educação) - Universidade Federal do Paraná, Programa de Pós-Graduação em Educação-Setor de Educação, Curitiba, 2013.

DRAGO, R. Inclusão na Educação Infantil. 2. ed. Rio de Janeiro: Wak Editora, 2014. GORETTI, A. C. S. A relação mãe-bebê na estimulação precoce: um olhar psicanalítico. 2012. 133 f. Dissertação (Mestrado em Psicologia) - Universidade Católica de Brasília, Programa de Pós-Graduação em Psicologia, Brasília, 2012.

HANSEL, A. F. Estimulação precoce baseada em equipe interdisciplinar e participação familiar: concepções de profissionais e pais. 2012. 139 f. Tese (Doutorado em Educação) - Universidade Federal do Paraná, Programa de Pós-Graduação em Educação - Setor de Educação, Curitiba, 2012.

HARLOW, H. F.; HARLOW, M. K.; HANSEN, E. W. The maternal affectional system of rhesus monkeys. RHEINGOLD, H. L. (org.) Maternal Behavior in Mammals. New York: John Wiley \& Sons, 1963. p. 254-281.

MENDES, E. G. Inclusão marco zero: começando pelas creches. Araraquara: Junqueira \& Marin, 2010. 
MULAS, J. P. Análisis de un modelo de seguimiento en atención temprana. 2007. 434 f. Tesis (Doctorado en Educación) - Facultad de Educación, Universidad Complutense de Madrid. Espanha, 2007.

NASCIMENTO, A. L. As primeiras aprendizagens da criança surda. 2010. 154 f. Dissertação (Mestrado em Letras e Ciências Humanas) - Universidade do Grande Rio "Prof. José de Souza Herdy”, Escola de Educação, Ciências, Letras, Artes e Humanidades, Rio de Janeiro, 2010.

OLIVEIRA, I. M.; PADILHA, A. M. L. Atendimento educacional especializado para crianças de zero a três anos. In: JESUS, D. M; BAPTISTA, C.R; CAIADO, K. R. M. (Org.). Prática pedagógica na educação especial: multiplicidade do atendimento educacional especializado. Araraquara: Junqueira \& Marin, p.197-218, 2013.

PAINEIRAS, L. L. Narrativas sobre estimulação precoce evidenciando as particularidades de crianças portadoras da Síndrome Alcoólica Fetal. 2005. 142 f. Dissertação (Mestrado) - Instituto Fernandes Figueira da Fundação Oswaldo Cruz, Rio de Janeiro, 2005.

PÉREZ-RAMOS, A. M. Q.; PÉREZ-RAMOS, J. Estimulação precoce: serviços, programas e currículos. 2 ed. Brasília: Ministério da Ação Social/Coordenadoria Nacional para Integração da Pessoa Portadora de Deficiência, 1992.

SÁNCHEZ-CARAVACA, J. La eficacia de los programas de atención temprana en niños de riesgo biológico: estudio sobre los efectos de un programa de atención temprana en niños prematuros en su primer año de vida. 2006. 303 f. Tese (Doutorado) Universidad de Murcia- Facultad de Psicología, Departamento de Psicología Evolutiva y de la Educación, Murcia, 2006.

SÁNCHEZ-CARAVACA, J.; GIL, I. C. Aplicación de programas de atención temprana siguiendo un modelo educativo. Educar em Revista, Curitiba, n. 43, p. 33-48, jan./mar. 2012. SOEJIMA, C. S; BOLSANELLO, M. A. Programa de intervenção e atenção precoce com bebês na educação infantil. Educar em Revista, Curitiba, n. 43, p. 65-79, jan./mar. 2012. TOZONI-REIS, M. F. de C. Metodologia da pesquisa. Curitiba: IESDE Brasil S.A., 2009. VYGOTSKI, L. S. Obras escogidas : fundamentos de defectologia. Traduccion Julio Guillermo Blank. Madrid: Machado Grupo de Distribucion, 2012. v.5. 